\title{
Rancang Bangun Aplikasi Sistem Basis Data Online Judge (SBDOJ) untuk Proses Pembelajaran Mata Kuliah Sistem Basis Data di Departemen Teknik Informatika ITS
}

\author{
Demsy Iman Mustasyar, Rizky Januar Akbar , dan Nurul Fajrin Ariyani \\ Departemen Teknik Informatika, Fakultas Teknologi Informasi, Institut Teknologi Sepuluh Nopember (ITS) \\ e-mail: rizky@if.its.ac.id
}

\begin{abstract}
Abstrak-Saat ini, praktikum Sistem Basis Data di Departemen Teknik Informatika ITS masih dilaksanakan secara manual. Ketika praktikan selesai mengerjakan soal, praktikan diharuskan memanggil asisten untuk mengecek jawabannya. Oleh karena itu diperlukan aplikasi yang membantu praktikum Sistem Basis Data agar menjadi lebih efisien. Pengujian difokuskan pada proses penilaian atau judgement. Proses penilaian dilakukan oleh grader yang dibangun dengan bahasa Python dan berjalan pada background. Pengujian dilakukan dengan melakukan uji coba beberapa jenis query. Query tersebut didapatkan dari praktikum Sistem Basis Data tahun 2015 dan 2016. Pengujian dilakukan untuk mengetahui tingkat keberhasilan grader dalam menangani proses penilaian query jawaban praktikan.
\end{abstract}

Kata Kunci-Sistem Basis Data, Online Judge, Grader, Python.

\section{Pendahuluan}

$\mathrm{B}$ ASIS data (database) adalah kumpulan data, biasanya menjelaskan mengenai aktifitas satu atau lebih organisasi yang terkait. Basis data terdiri dari entitas dan hubungan antar entitas. Basis data biasanya diatur menggunakan sebuah software yaitu Database Management System (DBMS). Basis data merupakan dasar dari sistem penyimpanan dalam sebuah aplikasi, baik itu aplikasi desktop, website, maupun mobile. Oleh karena itu teori-teori mengenai basis data harus dikuasai oleh semua developer perangkat lunak.

Di dalam matakuliah Sistem Basis Data (SBD) di Departemen Teknik Informatka ITS terdapat praktikum mengenai materi Data Definition Language (DDL) dan Data Manipulation Language (DML). Penilaian praktikum SBD saat ini masih manual, yaitu praktikan mengeksekusi query di DBMS lalu ditunjukkan kepada asistennya untuk dinilai. Sistem praktikum seperti ini tentu sangat tidak efektif, karena membutuhkan waktu lama dan membutuhkan sumber daya asisten yang banyak. Oleh karena itu, diperlukan sebuah aplikasi yang bisa membantu praktikum SBD tersebut. Aplikasi yang akan dibangun adalah Sistem Basis Data Online judge (SBDOJ).

SBDOJ memiliki konsep seperti online judge pada umumnya. SBDOJ merupakan aplikasi berbasis web. Aplikasi ini akan digunakan dalam praktikum SBD khusunya pada materi DML yaitu query SELECT. Praktikan diharuskan keberhasilanya. Dengan adanya aplikasi SBDOJ ini, mengumpulkan query jawaban dari sebuah soal, kemudian query tersebut akan dieksekusi oleh sistem dan akan dinilai diharapkan bisa mempermudah asisten maupun praktikan dalam praktikum SBD materi DML.

\section{TINJAUAN PUSTAKA}

\section{A. Online Judge}

Online Judge secara umum adalah server yang berisi deskripsi dari masalah dalam kontes yang berbeda. Serta data yang diatur untuk menilai apakah sebuah solusi tertentu menyelesaikan soal-soal yang berada di server tersebut [1].

Terdapat beberapa kategori online judge yang saat ini telah diimplementasikan, antara lain :

a. Problem Solving Online Judge

Online judge ini yang sangat familiar dan sering digunakan oleh para programmer untuk mengasah kemampuan logikanya dalam menyelesaikan problem set yang disediakan oleh online judge. Biasanya online judge ini digunakan untuk berlatih competitive programming. Contohnya adalah SPOJ, UVA, Toki Learning, dan masih banyak lagi.

b. HTML \& CSS Online Judge

Online judge untuk HTML dan CSS untuk saat ini masih berupa aplikasi untuk pembelajaran. Untuk itu online judge untuk CSS dan HTML terkadang dikenal dengan sebuutan online course karena tidak ada sistem rating untuk tiap soalnya. Sedangkan online judge seharusnya memiliki sistem rating. Contoh aplikasi online course HTML dan CSS adalah Codecademy dan FreeCodeCamp.

c. SQL Online Judge

Sama seperti online judge untuk HTML dan CSS, online judge untuk SQL saat ini masih berupa online course. Dikarenakan belum adanya sistem rating dalam aplikasi tersebut. Contoh aplikasi online course untuk SQL adalah Codecademy dan SqlCourse. 


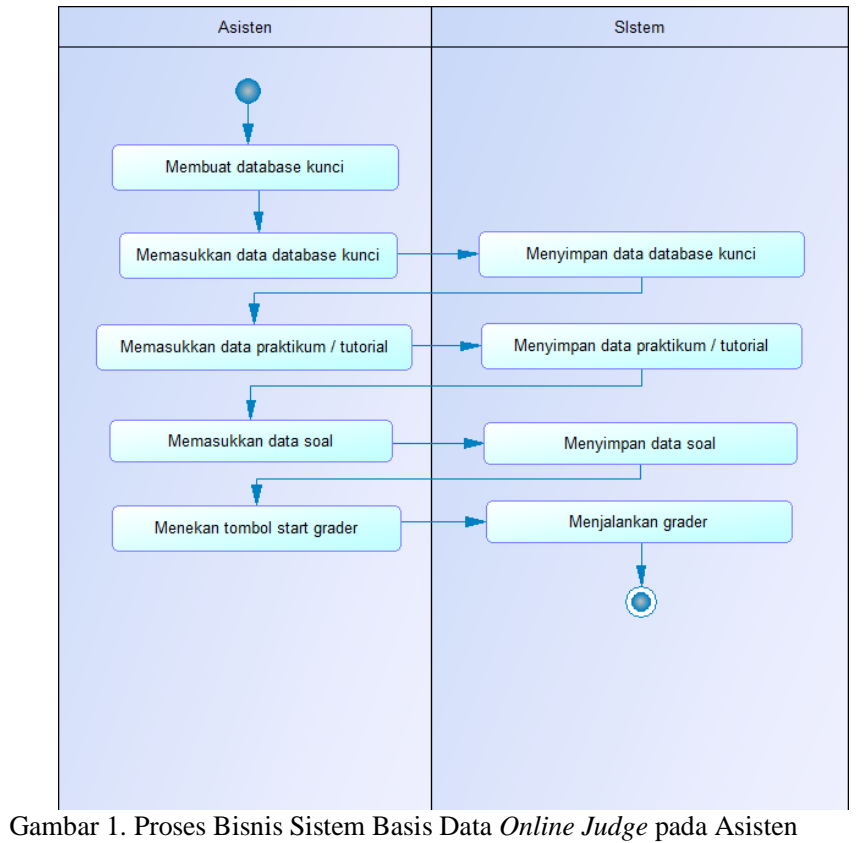

\section{ANALISIS DAN PERANCANGAN SISTEM}

\section{A. Analisis Sistem}

Sistem Basis Data Online Judge adalah aplikasi yang ditujukan untuk mempermudah penilaian praktikum Sistem Basis Data di Departemen Teknik Informatika ITS khususnya pada materi DML. Selain digunakan untuk praktikum, SBDOJ juga bisa digunakan asisten untuk memberi tutorial kepada mahasiswa. Di setiap event praktikum, terdapat scoreboard untuk melihat rekapitulasi nilai dari mahasiswa. Proses bisnis yang digunakan dalam aplikasi ini adalah proses bisnis yang umum terdapat pada online judge lainnya. Proses bisnis pada sisi asisten dapat dilihat pada diagram alir pada Gambar 1. Pada gambar tersebut, asisten harus memasukkan database kunci atau database yang akan digunakan untuk praktikum. Kemudian asisten harus membuat event praktikum atau tutorial. Langkah selanjutnya adalah membuat soal untuk praktikum tersebut. Soal harus disertai query jawaban yang benar dari asisten untuk proses penilaian. Kemudian asisten harus memulai grader dari database yang digunakan agar penilaian jawaban dari praktikan bisa berlangsung di background. Diagram alir dari sisi praktikan dapat dilihat pada

Gambar 2. Pada gambar tersebut, praktikan dapat memilih event praktikum atau tutorial. Event praktikum bisa dipilih apabila waktu sudah memasuki waktu mulai praktikum dan belum melewati waktu akhir praktikum. Praktikan kemudian memasukkan query jawaban pada soal yang dipilih. Setelah itu grader akan mengecek jawaban praktikan dan akan memberikan nilai dari jawaban tersebut. Nilai tersebut yang nantinya akan disimpan pada database. Pada aplikasi ini, data praktian dimasukkan oleh asisten masing-masing kelas. Jadi praktikan tidak bisa mendaftarkan dirinya.

\section{B. Perancangan Sistem}

Berdasarkan analisis sistem, didapatkan beberapa kebutuhan fungsional yang diperlukan untuk membangun

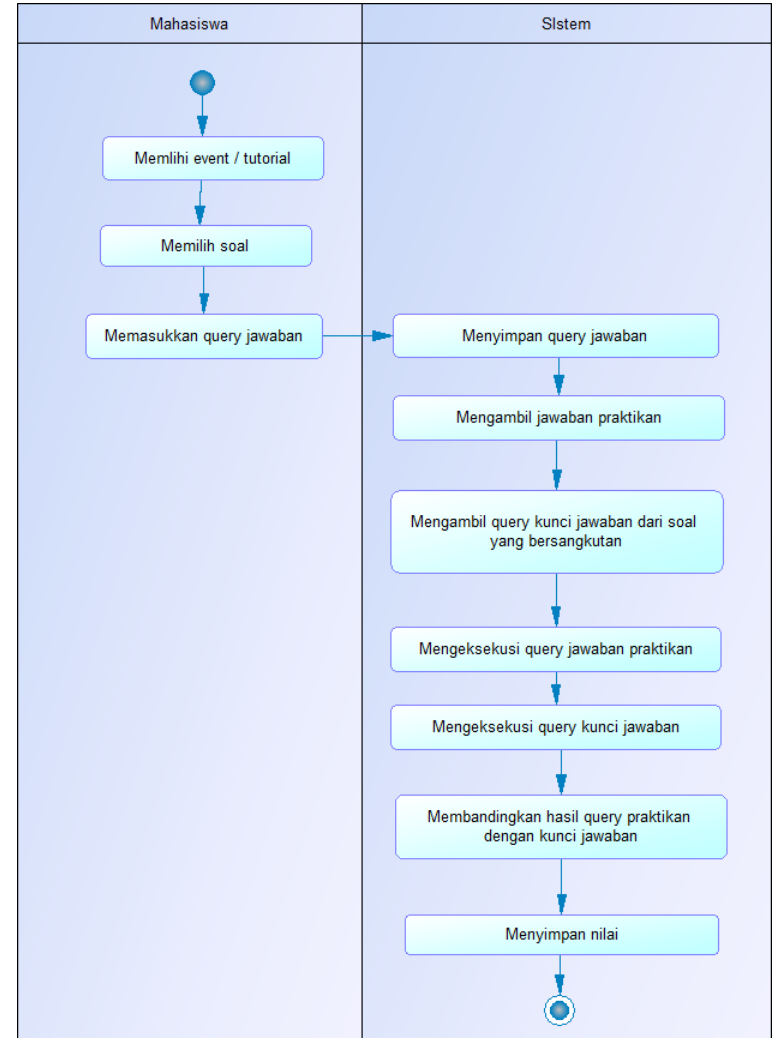

Gambar 2. Proses Bisnis Sistem Basis Data Online Judge pada Praktikan

aplikasi Sistem Basis Data Online Judge. Selain itu, dalam aplikasi ini juga terdapat dua pengguna yang terdiri dari asisten dan praktikan. Diagram kasus penggunaan aplikasi SBDOJ dapat dilihat pada Gambar 3.

\section{IMPLEMENTASI}

\section{A. Lingkungan Implementasi}

Dalam merancang perangkat lunak ini digunakan beberapa perangkat pendukung yang terdiri dari perangkat keras dan perangkat lunak. Spesifikasi perangkat keras yang digunakan dalam membangun aplikasi SBDOJ adalah sebagai berikut:

Jenis : : Personal Computer

Tipe : LENOVO 10132

Prosesor $\quad$ : Intel ${ }^{\circledR}$ Core $^{\mathrm{TM}} \mathrm{i} 3-4150 \mathrm{CPU} @ 3.50 \mathrm{GHz}$

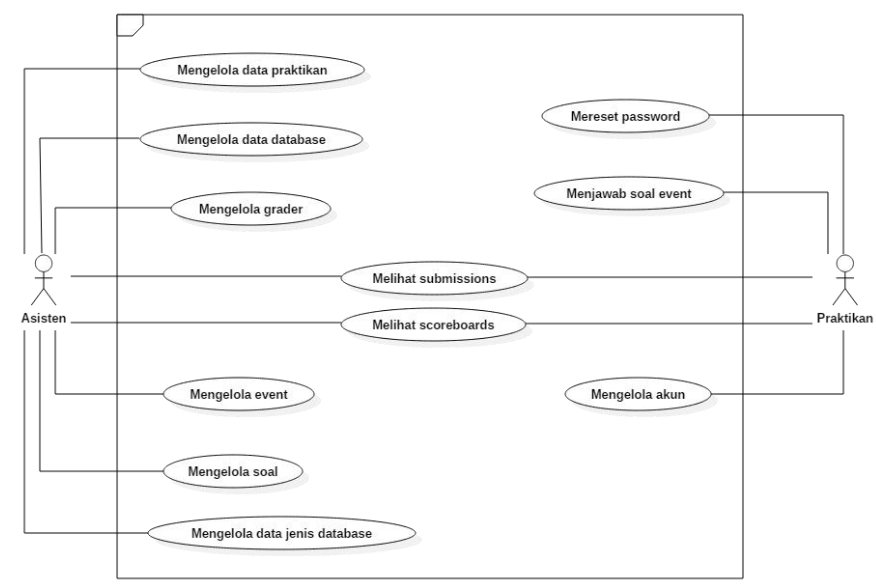

Gambar 3. Diagram Kasus Penggunaan 
Memori : 4096MB RAM

Sistem Operasi : Windows 10 Pro 64-bit

Perangkat lunak yang digunakan dalam membangun aplikasi SBDOJ adalah sebagai berikut:

- Sublime Text 3 digunakan untuk menyunting kode.

- StarUML 2.7.0 digunakan untuk membuat diagram kasus penggunaan, diagram aktivitas dan diagram kelas.

- Oracle SQL dan MySQL digunakan untuk antarmuka pengelola basis data.

- Apache digunakan untuk web server.

B. Implementasi Antarmuka

Antarmuka perangkat lunak dikembangkan menggunakan beberapa pustaka. Beberapa di antaranya adalah:

- Laravel Blade sebagai skrip bahasa utama,

- Semantic UI sebagai kerangka kerja CSS,

- jQuery sebagai kerangka kerja JavaScript, dan

- DataTables sebagai pustaka antarmuka tabel.

Halaman mengelola grader dan database dapat dilihat pada Gambar 4. Pada halaman ini terdapat halaman yang menampilkan daftar database yang dapat digunakan untuk praktikum maupun tutorial. Selain itu juga terdapat tombol

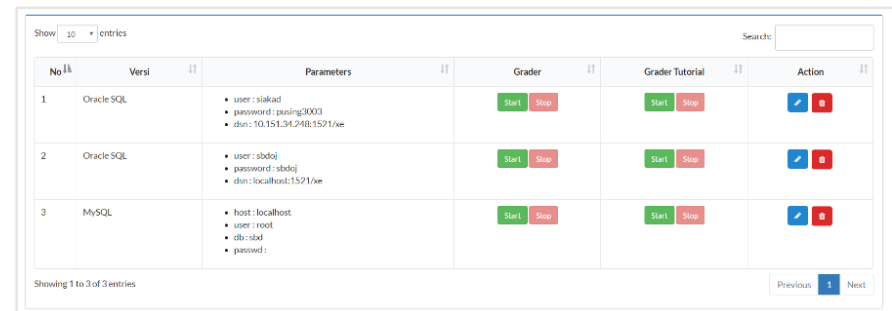

Gambar 4. Halaman Mengelola Grader dan Database.

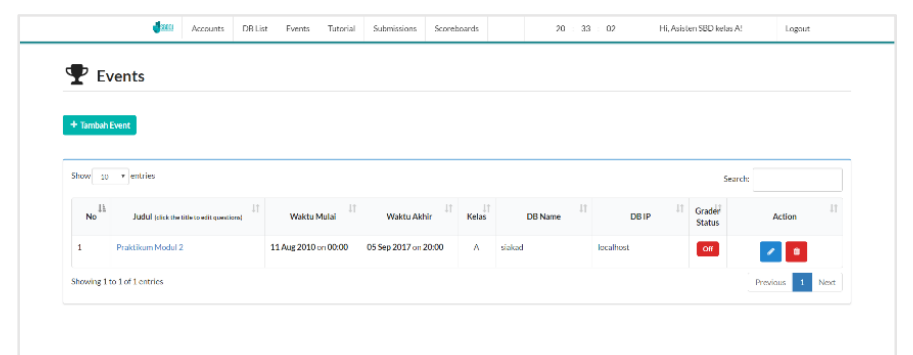

Gambar 5. Halaman Mengelola Event

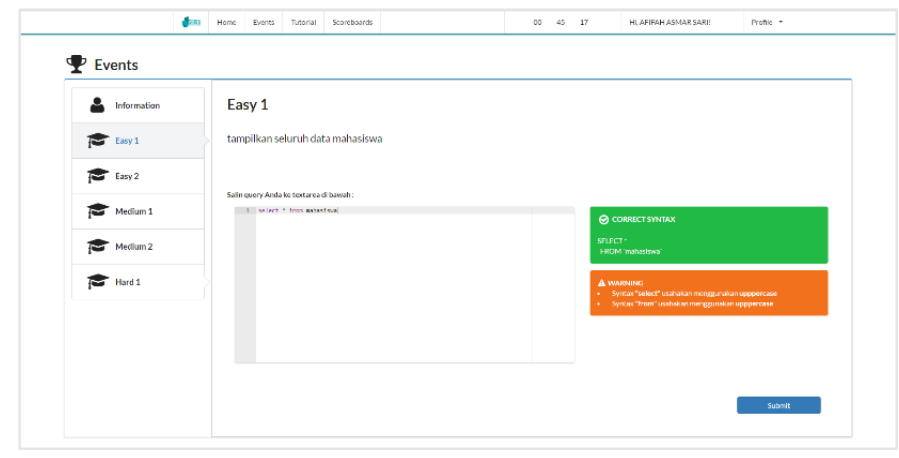

Gambar 6. Halaman Menjawab Soal Event

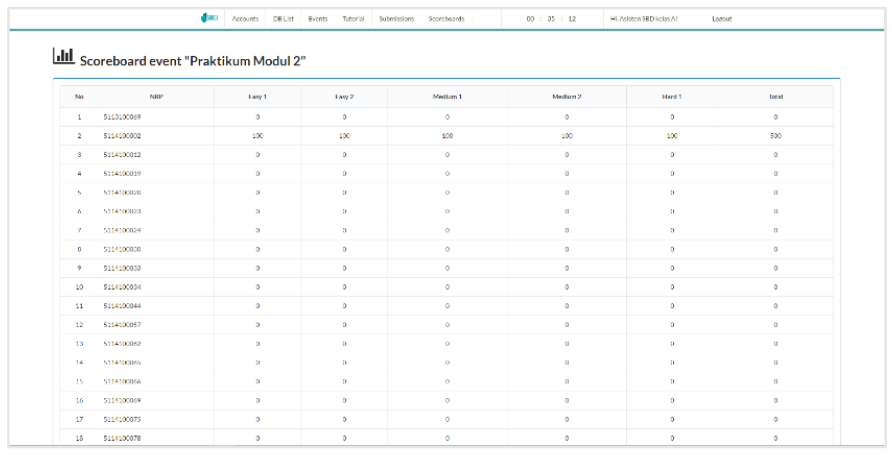

Gambar 7. Halaman Scoreboard

untuk memulai atau menghentikan grader pada masing-masing database.

Halaman untuk mengelola event dapat dilihat pada Gambar 5. Pada halaman ini terdapat tabel daftar praktikum atau tutorial yang berisi judul, waktu mulai, waktu akhir, kelas, nama database yang dipakai, status grader serta tombol untuk mengubah dan menghapus event.

Halaman untuk menjawab soal praktikum atau tutorial dapat dilihat pada Gambar 6. Pada halaman ini, soal ditampilkan dalam bentuk daftar tabulasi dan pada masing-masing soal terdapat field untuk memasukkan jawaban praktikan. Pada masing-masing soal juga terdapat SQL Parser untuk mengecek benar atau tidaknya syntax SQL dari praktikan.

Halaman untuk melihat scoreboard dari praktikum dapat dilihat pada Gambar 7. Halaman ini menampilkan tabel scoreboard dari suatu praktikum. Pada tabel tersebut terdapat nilai dari masing-masing praktikan pada masing-masing soal dan juga terdapat total nilai dari tiap praktikan.

\section{Pengujian dan Evaluasi}

Pengujian yang dilakukan adalah pengujian user acceptance test (UAT) dan pengujian sistem. Pengujian UAT bertujuan untuk mengetahui tingkat kebutuhan asisten akan aplikasi SBDOJ dan tingkat kesesuaian SBDOJ dengan kebutuhan praktikum SBD khusunya materi DML query SELECT di Departemen Teknik Informatika ITS. Jumlah responedn asisten adalah 5 orang. Sedangkan untuk pengujian sistem difokuskan pada tingkat keberhasilan grader dalam menangani proses judgement dari query yang memungkinkan terjadinya eror pada sistem. Pengujian grader dilakukan dengan menguji dua versi grader. Query yang diuji didapatkan dari praktikum SBD tahun ajaran 2015/2016 dan 2016/2017.

Setelah pengujian UAT dilakukan, dapat diketahui bahwa aplikasi SBDOJ sudah memenuhi kebutuhan praktikum SBD materi DML query SELECT dan dapat menghemat waktu asisten. Selain itu juga terdapat usulan dari asisten, yaitu penambahan bobot nilai tiap soal.

Kemudian untuk pengujian grader, dapat diketahui bahwa grader sudah dapat melakukan proses judgement dengan tepat dan sudah dapat menangani query yang melampaui waktu maksimal eksekusi (TLE). Namun terdapat kekurangan pada grader yaitu waktu maksimal eksekusi masih statis, yaitu 10 detik. Seharusnya waktu maksimal eksekusi dibuat dinamis berdasarkan soal dan jumlah row dari hasil query. 


\section{KESIMPULAN}

Selama proses perancangan, implementasi, dan pengujian dapat diambil kesimpulan sebagai berikut:

1. Aplikasi SBDOJ mampu menangani prosedur penilaian query jawaban dari praktikan dan dicocokkan dengan query kunci jawaban dari asisten.

2. Proses bisnis yang terjadi antara asisten dan praktikan dalam prosedur penilaian jawaban praktikan adalah sebagai berikut:

a. Asisten memasukkan data database yang akan digunakan untuk praktikum atau tutorial.

b. Asisten memasukkan data praktikum atau tutorial.

c. Asisten memasukkan data soal praktikum atau tutorial.

d. Asisten menekan tombol start pada grader yang dibutuhkan.

e. Praktikan memilih praktikum atau turorial yang diinginkan. f. Praktikan memilih soal yang diinginkan.

g. Praktikan memasukkan query jawabannya.

h. Grader mengecek dan menilai query jawaban praktikan.

3. Aplikasi SBDOJ sudah memenuhi kebutuhan fungsional .

4. Grader telah memenuhi kebutuhan proses judgement.

5. Berdasarkan user acceptance test, asisten membutuhkan SBDOJ untuk praktikum SBD materi DML query select.

\section{DAFTAR PUSTAKA}

[1] R. L. Miguel A. Revilla, Shahriar Manzoor, "Competitive Learning in Informatics: The UVa Online Judge Experience," Olympiads in Informatics, vol. 2, pp. 131-148, 2008. 